\title{
Implementation of Inclusive Approach to Teaching English as a Foreign Language
}

\author{
Nadezhda Pirogova \\ Foreign Language Training Center \\ ITMO University \\ Saint-Petersburg, Russia \\ E-mail: nadin040883@ rambler.ru
}

\begin{abstract}
This paper looks at the development of approaches to inclusive education and describes the peculiarities of basic types of SEBD and neurodiversity and their influence on language learning. Learners with special educational needs (SEN) can experience significant difficulties in the process of the second language acquisition. It outlines the ideas of professional development which is vital for foreign language teachers, and gives recommendations for the use of learning materials for inclusive practices. English language teachers should be aware of major problems that their learners with SEN often face in the classroom and try to create a learning environment conducive to language acquisition. The paper also addresses the problem of testing and assessment of students with special educational needs.
\end{abstract}

Keywords - inclusive education; neurodiverse learners, language teacher; special educational needs; communicative approach; multisensory activities; assessment; educational technology

\section{INTRODUCTION}

In the $21^{\text {st }}$ century the English language has become a global lingua franca. English language knowledge is considered to be the indicator of success in many spheres of life: from business, education and politics, to tourism and entertainment and daily communication. However, the educational environment of many language learners with special needs does not always take into account their individual differences. The primary goal of inclusive education is to actively engage all students in learning and help them reach their potential. Inclusive education supports the principle of equity and takes into account that all students have their strengths and weaknesses. As claimed by UNESCO, 'Inclusion is a process that helps overcome barriers limiting the presence, participation and achievement of learners' [1].

Inclusive teaching and learning are based on four core values proposed by the European Agency for Development in Special Needs Education in 2012:

1. Valuing learner diversity - learner difference is considered as a resource and an asset to education;

2. Supporting all learners - teachers have high expectations for all learners' achievements;

3. Working with others - collaboration and teamwork are essential approaches for all teachers;

4. Continuing personal professional development teaching is a learning activity and teachers take responsibility for their own lifelong learning [2].
It is difficult to calculate how many people have difficulties due to cognitive peculiarities. Many of them are not formally identified and the identification criteria differ from country to country. According to recent statistics, there are 800 million children around the world who experience psychological or physical difficulties [3]. Basically, there are 2 groups of such learners - neurodiverse learners (with specific learning problems such as dyslexia) and SEBD learners (with social, emotional and behavioural difficulties). Foreign language teachers can benefit greatly from learning about key features of SEBD and neurodiversity.

The term SEN (special educational needs) was first used by H.M. Warnock in the report in 1978 [4] and is widely used in educational institutions. The definitions of SEN differ a lot in various countries and the term should be used carefully because it means different things to educators and students. It may seem to have a negative connotation because it sets the learners apart from their peers. The term "neurodiversity" is mostly applied to students with SEN, such as autism, dyslexia and ADHD (attention deficit hyperactivity disorder). Neurodiversity implies the idea that our human brains operate differently, and some more actively than others.

In 2007, Organisation for Economic Co-operation and Development (OECD) worked out the classification of special educational needs that fall into three types:

A) disabilities (sensory, motor and neurological impairments)

B) difficulties (behavioural or emotional disorders, or specific difficulties in learning)

C) disadvantages (difficulties arising from socioeconomic, cultural, and/or linguistic factors [5].

The paragraph below gives a brief overview of the key disorders in language learning that inclusive education deals with.

Students with dyslexia are unable to recognize and discriminate between English sounds or memorize and use grammar structures in context. It is hard for them to acquire good literacy skills and they need a lot of practice to remember new vocabulary. Children with dysgraphia have illegible handwriting and are unable to maintain margins and lines. Their spelling and grammar are often inaccurate, and the text structure is incoherent. Another disorder that learners may experience is dyspraxia or DCD (developmental coordination disorder) [6] that makes it hard for them to plan and sequence movements. The teacher may notice that students with dyspraxia can have problems in 
organizing their work space and working quickly to finish the task on time. They often mispronounce sounds and use them in incorrect order. When learning a language students with different forms of autism can experience difficulties working in pairs and groups, in role-playing imaginary situations. Kids with ADHD (attention deficit hyperactivity disorder) find it difficult to follow teacher's instructions and take turns in games and conversations.

The foreign language teachers may be the first to notice the signs of SEBD or neurodiversity during their classes. Students with SEBD may possess low self-esteem and demonstrate their disengagement in different ways: disrupt the classroom routine, daydream or waste time during classes. Some students, on the other hand, may study too hard to perform the task and suffer of the burnout as the result. Many neurodiverse students often need visual aids (colourful diagrams, pictures, flashcards) to understand and memorize new material. Learners with SEBD often feel anxious and vulnerable, that is why they often can't focus on work. They are not always able to manage their feelings around learning. Sometimes students have SEBD as a result of neglect, loss, conflict, or trauma.

At the same time, English language classroom provides a perfect environment to implement the idea of inclusive education that allows all students to achieve academic success. The collaborative and communicative approaches in language teaching provide important opportunities for inclusive education. English language teachers often have profound knowledge of these approaches and can effectively facilitate cooperation between learners during the classes. Teachers can notice certain strengths in learners with SEN. For instance, students with autism spectrum condition sometimes possess perfect memory for rules and facts, making them good at English grammar. They may be interested in a specific topic or project work. Learners with ADHD are often very active and prefer to be engaged in a variety of tasks and practical activities, drama and art projects, motivating their peers to participate. Language teachers can inspire and motivate their students with SEN by giving oral praise for their efforts and individual achievements.

Reaching full inclusion or integration may present a great challenge for teachers in educational institutions of all levels - kindergartens, schools, colleges, universities. The implementation of inclusive educational system must be supported at an institutional level and teachers must be provided continuous professional development (CPD). The next section gives further details of inclusive education that are useful for language teachers to know as part of their professional development.

\section{ADOPTING INCLUSIVE TEACHING METHODS}

English language teachers can successfully apply student-centered, task-based and communicative approaches in their inclusive classes. These approaches are mostly based on learner-to-learner communication, foster cooperation and collaboration between students.

In order to succeed in inclusive education teachers should carefully plan their language course, set the goals and develop the procedure for each lesson. The teacher should also think over the range of teaching techniques and materials. The tasks that students will engage with should be varied and achievable. The materials should include multimodal resources for multisensory activities. The classroom environment also plays an important role. Good lighting, mild temperature and low noise levels are necessary for comfortable studying process. While being assessed, students can demonstrate their progress in various formats. Language teachers should provide constructive and explicit feedback, focusing on the key areas for language development.

The practical solution to the problem of individual differences in the way children learn is differentiation. All students, especially those with cognitive peculiarities, work at their one pace, and in their own style. Differentiated approach means getting an overall knowledge of neurodiversity and all the details about how individual students with SEN learn so that they can be provided with alternatives which help them become autonomous.

It is important to note that there is no single method that will be suitable for every student. With practice and experience, however, language teachers can learn from mistakes and improve their teaching techniques.

Teachers may prepare various text types in different formats and let learners choose which materials to tackle. Teachers should admit that not every student will fulfill the same number of tasks during the lesson. Instructors and teachers should bear in mind that in most cases the learning process is more important than the result. Groupwork can help learners in mixed-ability classes to balance their skills, allowing teachers to pay more attention to students who need extra clarification or assistance at a certain point in the class.

Outside the classroom teachers can share their positive and negative experiences, discuss how to cope with learning difficulties encountered by their students. Teachers can also study for extra qualifications to learn more about inclusive practices around the world or take an online course on issues related to inclusive education. Some international organizations can help teachers socialize with their colleagues who are involved in inclusive education worldwide. For example, IATEFL (International Association of Teachers of English as a Foreign Language) has a special interest group named Inclusive Practices and SEN, which unites teachers dealing with learners who have special needs.

\section{PUTTING INCLUSIVE THEORY INTO PRACTICE}

Experienced language teachers usually know their students well, they understand their potential and difficulties they face. Differentiation is a method that teachers and instructors use when they teach a familiar group of learners. They choose a particular student to give an answer to the question, put students together in pairs or groups and allocate tasks so that learners can complete them successfully.

Modern English language courses are presented with a range of digital and print components that greatly improve learning and teaching experience, giving more opportunities and flexibility to students with SEN, who can get access to educational content in alternative ways. Very often small adjustments to the traditional coursebook activities can be 
beneficial for neurodiverse students. For the majority of students, textbooks are interesting and visually appealing, with colourful pictures motivating students for learning. On the other hand, students with ADHD often find it difficult to focus on certain material, and learners with dyslexia find visual information overburdening.

The solution to this problem can be the use of two pieces of card (text windows) that can help students to concentrate on one part of the page. The digital solution can be the use of special online resources - audio files of text for reading that can be slowed down. Multimodal resources include digital materials such as video, interactive whiteboard materials, applications that help with vocabulary acquisition. Real objects and traditional paper materials are also important, as they make language learning process relevant to the real world.

It is important to mention that there is no single solution that is appropriate for all students. That is why teachers should try out different solutions and get constructive feedback from their students, creating the atmosphere of openness and trust. Language teachers can work on various strategic and technical skills with their students and choose the best ones that are important to succeed in listening, reading, speaking and writing activities.

Thus, the teachers can boost efficiency of textbook activities for students. Some traditional tasks can have an overload on working memory, which can present a number of difficulties for neurodiverse students. For instance, a 'listen and do' task that involves translation, paraphrasing and summarizing, or 'reading while listening' exercise, which makes students process a lot of information at once, can be inappropriate for students who experience problems with phonological processing and working memory. The task can be less difficult for students if the action part requires students to show the understanding in a nonverbal way, such as choosing a picture, completing the mind map or colouring.

Multisensory activities can be conducive to the inclusive language learning. These activities include more than one of the senses - hearing, sight, and touch. Using several senses simultaneously has two pluses: the number of memory routes grows, and the learner participation increases. Good multisensory tasks do not make students perform different activities simultaneously, because it would overload their working memory.

Flow charts, mind maps, timelines and diagrams are simple and efficient visual aids that can be used to demonstrate relations between ideas, or to summarize key information. They can significantly enrich language experience for neurodiverse students. For instance, the conventional, oral presentation of grammar topics in tables is suitable for students with analytical mindset, but some students will benefit more from the use of flow charts and mind maps, which offer a more memorable presentation of the same information. Teachers should also encourage physical contact with learning resources to stimulate students' auditory, visual and kinaesthetic channels of perception. Singing English songs and jazz chants are multisensory activities which can be incorporated into the classroom routine.
Language teachers prefer to use authentic materials during their classes. However, students with SEN will greatly benefit from using adapted materials in which information is presented in a simple way, with less information on one page. Teachers may use such adapted materials in a flexible way: they can serve as extra resources for the classroom use, and all students can choose them when necessary. It will help to avoid the formation of a separate group of learners with SEN using different materials. Teachers may ask students to prepare adapted material such as glossaries or quizzes. All students will be engaged in creative activities, making a contribution to the inclusive environment.

Students can also work together at home to prepare materials for the class use. These can be visual mind maps, posters and simple grammar worksheets. This can be a good way to revise material for students who are already familiar with the topic from the coursebook and introduce new information to learners who are unfamiliar with it yet.

Some learners who find communication difficult can be asked to work with one or two other students, in short activities that will be comfortable for them. Before working in small group the students need some time to get ready individually. Different games give students great opportunities to understand the importance of such skills as working together and turn-taking. It is useful for inclusive learning if the teacher can efficiently arrange the layout of the classroom to promote interaction. For example, they can put chairs into pairs, or lay out desks for the individual or group work. The teacher can also minimize distraction typical for ADHD by seating them away from the window so that they won't be overexcited.

One of the key impacts language teachers can have on their neurodiverse students is to help them understand themselves in a deeper way, and to work out their most efficient ways of studying and becoming independent learners. In this case the students will be able to study more confidently and achieve their goals. Teachers should do their best to provide students with strategies for dealing with new problems, using their individual features and talents. Very often students with SEN don't know how to start the activity, or to finish it, because of obstacles to learning such as being unable to memorize English vocabulary or grammar rules, or not having enough time to complete the task. By identifying what the problem is, learners can work out the solution to it. For instance, some children with SEN can be overloaded by the amount of textual information in reading activities, and will need clear instructions in order to cope with the task. Modern coursebooks often contain tips with useful strategies that students can use, such as predicting content from the pictures and title, previewing the text and some lead-in tasks.

Students who experience greater difficulties on the daily basis can benefit a lot from developing self-awareness and positive self-esteem. Teachers play an important role it the formation of self-esteem, because their oral praise and positive evaluation of students' achievements are really important. If students believe in their personal success, and are motivated to recognize their strengths and progress, they will be more willing to go an extra mile and not to give up when faced with a difficulty. 


\section{ASSESSMENT OF LEARNERS WITH SPECIAL EDUCATIONAL NEEDS}

Testing and assessment play a vital role in learning and teaching, and it is necessary for teachers to keep in mind that all difficulties that learners face in studying may be increased in the assessment procedure. Teachers should decide if they will apply the same criteria for assessing the results of students with SEN as for their peers. In some countries, these learners have personalized learning plans with individualized evaluation criteria.

Learners' proficiency levels are usually evaluated by means of summative assessment or assessment of learning. This kind of assessment is performed by international testing organizations. This type of assessment is formal and is important for getting school-leaving qualification, high school entrance and employment. Such formal and difficult examinations can be really frightening for neurodiverse students and learners with SEBD. That is why it is important to assess students' achievements taking into account their strengths and weaknesses, and using the results to choose the best learning methods. This type of assessment is known as formative assessment or assessment for learning [8] and can be conducted formally and informally.

Neurodiverse students can benefit a lot if they achieve the goals that are below their age and level. Learners can also set their own goals and evaluate progress. Some students can also set targets that help them to evaluate not only their learning progress but also their emotional, social and behavioural achievements. Teachers and instructors can use different techniques to help learners record their achievements. These can be class pictures or checklists of targets.

It has been already mentioned that students with SEN can benefit from multisensory activities. Teachers can also efficiently apply multisensory approach to classroom testing and assessment. For instance, to check comprehension of a grammar aspect or a reading text, a teacher can ask learners to demonstrate their understanding by drawing symbols, pictures, or mind maps. They can show what they know by recording some audio or video. Another useful instrument that can be used for evaluation is self-assessment. Assessing their own achievements gives students a good chance to understand what skills they need to improve. It also promotes students' autonomy and raises their self-esteem, because learners are encouraged to take responsibility for their learning [7]. One more advantage is that learners compare their results with their previous achievements, so they can concentrate on their own progress.

Another type of informal assessment that can be conducive to inclusive practice is peer assessment. Teachers should give their learners some ideas on how to assess each other in a supportive and constructive way. An example of training activity can be the task in which students are asked to identify two things they like in their classmate's work, and then choose and explain one aspect that should be improved.

Different types of testing are widely used as one of the most reliable type of assessment in ELT nowadays. Unit and progress tests included into teacher's packages can help them monitor learners' performance. However, teachers have to adapt them to make them more appropriate for students with SEN. First, the tests should be examined by the teacher to make sure that the types of tasks, structure of the test and instructions are clear enough. After that the teacher can adapt the test, taking into account specific needs of learners. For example, students with dyslexia who often have problems with quick auditory processing, may feel uncomfortable during listening activities, especially if the time limits are set. Therefore, they should be given extra time to listen to the recording. Teachers may also set different goals for some learners in reading and writing in English, and focus on achieving proficiency in such skills as listening and speaking. For students with autism, the assessment of interaction skills is especially challenging and it is important to organize learners' communication in pairs or small groups. Some students with SEN may be tested on vocabulary and grammar knowledge as well as on receptive and productive skills, but the expected result may be lower in comparison with their classmates.

Teachers should consider some important things when they work with students who regularly face difficulties in language learning. For example, teachers should tell their students in advance about progress and final tests, and help to get ready for them to avoid stress and nervousness. Tests present an additional load for learners who work with information more slowly than others, and it increases their anxiety. Extra time $(25-50 \%)$ to finish the activities can be the solution to the problem. Some students also need short breaks during the test to make up for concentration difficulties. Some neurodiverse learners have a rather short attention span. That is why the number of questions in the tasks can be decreased, listening recordings and reading texts can be divided into several parts. Easy and clear visual presentation of information helps all students, and it is especially important for learners for whom logical operations are challenging. Tests printed on coloured paper and big font size can help students to avoid visual stress. Teachers can test their neurodiverse students without giving them formal grades and provide feedback in the form of short comments. It helps students to concentrate on what that have done successfully and what needs improvement without comparing their results with their peers' work. Learners with SEN have to be praised for their good results, even if they fall short of the accepted standards.

In general, for the language testing to be valid, it is vital that more than one type of task is presented for evaluating learners' performance [9]. Preferably, activities should be presented in such a way that gives learners a sense of achievement and bring chances of failure to a minimum. Tests should be motivating, interesting and useful [10]. For learners with SEN who don't like changes, it is desirable to include into the test the tasks similar to the tasks they have come across before.

Some modern technologies can help neurodiverse students with formative assessment. They can help to overcome learning difficulties, allowing learners to use alternative ways of demonstrating their comprehension and show easily what they understand. For instance, text-tospeech technology can help learners with reading problems to cope with reading comprehension activities. There are a lot of educational technologies and more are being introduced all the time. So the teachers and instructors 
should check what is available and choose what is better for individual learners.

Learning management system (LMS) is a good example of effective educational technology. Teachers can place the assignments for students onto this platform, and learners can conveniently complete them online. It is worth pointing out that learners may not immediately react positively to a new technology, especially if they have no experience of it or are used to getting grades. Therefore, teachers should introduce new approaches and technologies gradually, giving clear explanations and providing encouragement and assistance. Learners will gradually understand the importance of new technologies and finally become more autonomous learners.

\section{CONCLUSION}

To summarize, it should emphasized that inclusive education must be planned on two levels: the development of a generally positive inclusive environment full of respect, support and motivation, as well as implementation of individual approach to each learner with special educational needs. Approaches to inclusive education have been developing over the last years and many institutions include inclusive practice in their learning programmes. On the other hand, it is accepted that foreign language learning is especially challenging for students with special educational needs. Nevertheless, new teaching approaches based on interactive strategies can provide a perfect environment for language learning and address these challenges.

Inclusive education means taking into account peculiarities of all students within the group of students, appreciating the contribution made by each learner, and trying to make the curriculum clear and accessible to everyone. Inclusive learning is based on the idea of equity, in which each student is given what they require in order to become academically successful. It is important that inclusive learning is beneficial for all students. The advantages incorporate social benefits, because learners' positive attitude to diversity grows, and they develop empathy for others, as well as pedagogical benefits, because teachers try to make their lessons more accessible and motivating.

Teachers and instructors play a key role in the development and adaptation of inclusive programmes, but they can't succeed without getting support from other groups of people - school and university staff, learners' families and children themselves. Implementing inclusive approach leads to creation of a new educational system where all students have good chances to learn successfully.

\section{REFERENCES}

[1] UNESCO. A guide for ensuring inclusion and equity in education. Paris: UNESCO, 2017, p. 7

[2] European Agency for Development in Special Needs Education. Profile of inclusive teachers. Odense: European Agency for Development in Special Needs Education, 2012, p. 9

[3] B. Carpenter. Early childhood intervention: Possibilities and prospects for professionals, families and children // British Journal of Special Education, 2005, 32(4), pp. 176-183.

[4] H. M. Warnock. Special educational needs: Report of the committee of enquiry into the education of handicapped children and young people. London: HM Stationery Office, 1978, 416 p.
[5] Organisation for Economic Co-operation and Development (OECD). Students with disabilities, learning difficulties and disadvantages: Policies, statistics and indicators. Paris: OECD/CERI, 2007, p. 4.

[6] J. Gibbs, J. Appleton, R. Appleton. Dyspraxia or developmental coordination disorder? Unravelling the enigma // Archives of Disease in Childhood, 2007, 92 (6), pp. 534-539.

[7] H. Gholami. Self assessment and learner autonomy // Theory and Practice in Language Studies, 2016, 6 (1), pp. 46-51.

[8] V. J. Shute, Y. J. Kim. Formative and stealth assessment / Handbook of research on educational communications and technology, New York, NY: Springer, 2014, pp. 311-321.

[9] J. Kormos, A. M. Smith . Teaching languages to students with specific learning differences. Bristol: Multilingual Matters, 2012, 232 p.

[10] M. Kung, J. Fitzgerald, S.J. Amendum. Using curriculum-based assessment to identify young second-language learners' risk for delayed second-language reading progress / Assessing L2 students with learning and other disabilities. Newcastle-upon-Tyne: Cambridge, Scholars Publishing, 2013, pp. 93-110. 